\title{
Integrating mobile bed numerical modelling into reservoir planning operations: the case study of the hydroelectric plant in Isola Serafini (Italy)
}

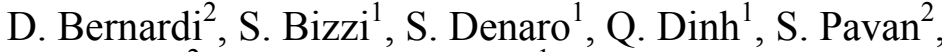 \\ L. Schippa ${ }^{2} \&$ R. Soncini-Sessa ${ }^{1}$ \\ ${ }^{I}$ Department of Electronics, Information and Bioengineering, \\ Politecnico di Milano University, Italy \\ ${ }^{2}$ Department of Engineering, University of Ferrara, Italy
}

\begin{abstract}
This work aims at integrating the understanding of the river geomorphic dynamic into the planning of reservoir operation rules. The case study is a $112 \mathrm{~km}$ long reach of the Po river in Italy, from Piacenza to Boretto. The Isola Serafini (IS) gate has served a large run-of-the-river hydroelectricity plant since 1962. The dam blocks a relevant amount of sediments and is the cause, together with intense sand mining, for the river bed incision immediately downstream that has made several navigation and irrigation devices unusable during low flow periods, leading to expensive and recurrent works to restore their functionality. The operational rule of the IS gate was modelled using 4 parameters and a number of experiments were simulated adopting alternative operating policies over a 10year period. A 1D hydraulic numerical model with mobile bed has been used to estimate bed degradation trends. The results show that there is space for a meaningful trade-off between the conflicting objectives of hydropower production and reduction of river bed degradation. The analysis provides operative rules able to effectively tackle river bed incision with moderate loss in hydropower production.
\end{abstract}

Keywords: multi-objective water resources management, fluvial geomorphology, $1 D$ hydraulic modelling. 


\section{Introduction}

Reservoir operations are commonly planned in order to maximize objectives related with hydropower generation, water supply and flood mitigation. However, reservoirs strongly influence river geomorphic processes, causing sediment deficit downstream, altering the flow regime, leading often to river bed incision [10]. Notwithstanding that, the operational rules of reservoirs are planned considering objectives such as maximizing hydropower production or supplying water for irrigation [2], and the effects of such policies in terms of river geomorphic processes are often neglected in the designing phase.

Our case study (fig. 1) is a $112 \mathrm{~km}$ long reach of the Po river in Italy, running from Piacenza to Boretto, that includes the run-of-the-river hydroelectricity plant of Isola Serafini (IS). The power station, managed by the Italian energy agency ENEL, is served by a $350 \mathrm{~m}$ wide dam and has a total capacity of $80 \mathrm{MW}$. The incoming discharge is partially diverted to the hydropower plant channel, which originated as a meander cut-off during the huge 1951 flood and rejoins the Po river about $12 \mathrm{~km}$ downstream of the gate, after a large meander. The IS dam has eleven vertical sluice gates, all of the same width. Six of them can also work as sharp-crested weirs.

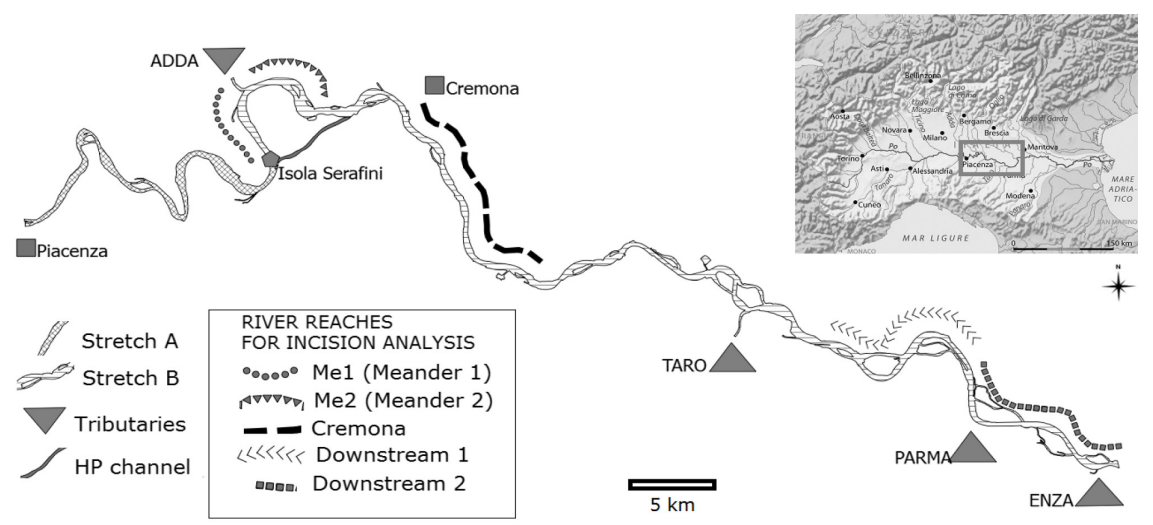

Figure 1: $\quad$ Scheme of the case study.

River Po environmental services are widely exploited. For instance, River Po is the longest waterway in Italy and is the main irrigation supply to the Po Valley, the richest and most productive agricultural area in Italy. Its high quality sands are suitable for construction and were significantly exploited in past decades.

Due to intense sediment mining as the main cause, the middle course of the Po underwent a strong river bed degradation process in the years from 1950 to 2000 , characterized by severe rates until the 1980 s. It is assumed that instream mining arose from 3 million $\mathrm{m}^{3} /$ year to 12 million $\mathrm{m}^{3} /$ year in the period from 1960 to 1980 , then decreased back to 4 million $\mathrm{m}^{3} /$ year [7]. Recently, stricter regulations on instream sediment mining have partially stopped this activity. 
Along with sediment mining, also low water training for navigation purposes and the presence of dams in the upper part of the Po basin affect the overall sediment balance along the middle course. In addition, the presence of the IS hydropower plant has played an important role since 1960 when it was built. The IS barrage is trapping sediment upstream, causing an abrupt decrease in sediment supply downstream and affects the hydrological regime reducing the transport capacity of the river in the meander downstream.

River bed incision downstream of the IS dam is well visible looking at the minimum water stages per year recorded at Cremona station, decreasing by more than $4 \mathrm{~m}$ from 1950 to 2000 (fig. 2). Moreover, Cremona harbour structures (e.g. navigation locks) have been severely affected by the lowering of the river bed and some of them have had to be completely rebuilt by means of expensive interventions. River bed incision also leads to issues such as instability of infrastructure, such as banks and bridges, along the river; in addition, it potentially decreases the water table and can alter important ecological processes of the freshwater environment [14].

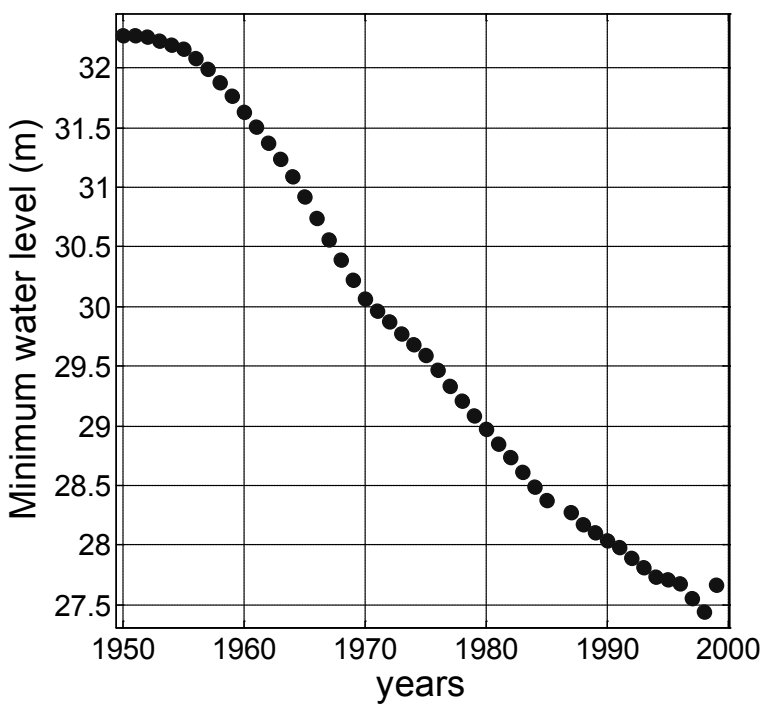

Figure 2: $\quad$ Minimum water levels recorded at Cremona gauging station.

The objective of this research is to assess if a better management policy of IS gate exists, able to mitigate the river bed lowering without significantly affecting hydropower production. To evaluate the effects of the different policies, a physically based one-dimensional numerical model, able to represent 1D flows with a mobile bed in natural channels of complex geometry has been used.

The proposed case study aims at developing a framework to provide river managers with tools to critically compare the effects of alternative operational policies at the IS gate in terms of river geomorphic processes. The findings allow us to analyse the trade-off between hydropower production and river bed 
incision, and open the way to plan sustainable and cost-effective measures in the long term.

\section{The numerical one-dimensional model}

The choice of a one-dimensional model permits us to represent the main geomorphic processes of interest in our case study (i.e. river bed incision) and at the same time to limit the computational time required for the several experiments planned.

\subsection{Governing equations}

The model is based on a set of three differential equations, stating mass and momentum conservation for the liquid phase and mass conservation of the solid phase along the main stream direction [13].

$$
\begin{gathered}
\frac{\partial A}{\partial t}+\frac{\partial Q}{\partial x}=q \\
\frac{\partial Q}{\partial x}+\frac{\partial}{\partial x}\left(\frac{Q^{2}}{A}+g I_{1}\right)=\left.g \frac{\partial I_{1}}{\partial x}\right|_{z w}-g A S f \\
(1-p) \frac{\partial A_{b}}{\partial t}+\frac{\partial Q_{s}}{\partial x}=q_{s}
\end{gathered}
$$

In the equations $t$ is the time, $x$ is the longitudinal stream coordinate, $A$ is the cross-section wetted area, $Q$ is the liquid discharge, $\mathrm{g}$ is the gravity acceleration, $I_{l}$ is the static moment of the wetted area $A$ with respect to the water surface, $S_{f}$ is the friction slope, $A_{b}$ is the sediment volume per unit length of the stream subject to erosion or deposition ("sediment area"), $Q_{s}$ is the solid discharge, $q$ and $q_{s}$ are the liquid and solid lateral inflows (or outflows) per unit length, respectively.

Formulation (2) of the momentum conservation law allows us to balance momentum correctly in non-prismatic channels without an explicit definition of the local bottom slope $[12,15]$ which is undesirable because it can lead to an incorrect evaluation in natural rivers, where changes in bed slope are sudden. The first term on the right-hand side of (2) represents the variation of the static moment $I_{l}$ along the x coordinate at a constant water level $z w$.

For slope friction, the common Manning formula has been used:

$$
S f=\frac{n^{2} Q^{2}}{A^{2} R^{4 / 3}}
$$

An equivalent resistance coefficient $n$ over the cross section, taking into account the different roughnesses between main channel and overbanks, has been calculated. For solid discharge the Engelund-Hansen [4] formula, which simply relates solid discharge to liquid discharge, has been chosen. Previous 
studies on the Po river [6] pointed out that this formula is the most suitable to correctly represent sediment movement in the Po river.

$$
q_{s}=0.05 \cdot \rho_{s} g U^{2} \sqrt{\frac{d_{s}}{g(s-1)}} \cdot\left(\frac{\tau_{0}}{\rho g(s-1)}\right)^{3 / 2}
$$

In (5), $q_{s}$ is the solid discharge per unit width; $\rho$ and $\rho_{s}$ are the densities of water and sediments, respectively; $s$ is the relative density $\rho_{s} / \rho ; d_{s}$ is the sediments representative diameter; $U$ is the water average velocity; $\tau_{0}$ is the bed shear stress.

\subsection{The bed evolution model}

The solution of the balance eqn. (3) updates the value of sediment area $A_{b}$ at every time step. This value has to be converted into a bed elevation variation, $\Delta s$, for every wetted point of the cross section. It is assumed herein that this variation $\Delta s$ is proportional to bed shear stress, which in turn is related to the local water depth $h$ through a proportionality constant $k$ :

$$
\Delta s=k h
$$

The variation of sediment area $\Delta A_{b}$, at every time step, is given by integrating $s$ along the wetted perimeter $P$ :

$$
\int_{P} \Delta s d p=\Delta A_{b}
$$

Applying the same integral to the right-hand side of (6) leads to the integral of the water depth along the wetted perimeter, which is in fact the wetted area $A$. It follows that

$$
k=\frac{\Delta A_{b}}{A}
$$

and the local bed elevation variation due to erosion or deposition is calculated directly by (6).

\subsection{The numerical scheme}

The finite difference explicit scheme developed by McCormack [8] has been chosen to integrate the set of equations (1)-(3), for its simplicity to implement and ability to cope with discontinuities in the solution (shock-capturing). It is based on a predictor-corrector procedure, where forward spatial finite differences are used in the predictor step and backward differences in the corrector step. Source terms are calculated with predictor values of state variables. In subcritical flow regime, upstream boundary conditions for liquid and solid discharge and a downstream boundary condition for water level are needed. 


\subsection{Application of the model to the case study}

The cross sections along Po river are available from the topographical surveys by AIPO (Interregional Po Agency), carried out in 2009. There are 67 surveyed cross sections in the reach of interest; one every $1.69 \mathrm{~km}$ on average. On every cross section survey, the boundaries of the overbanks and the thalweg are identified: then, to improve spatial accuracy, cross sections are interpolated up to a space interval of $450 \mathrm{~m}$ ( 250 cross sections).

The river stretch is split in two sub-stretches, A from Piacenza to the IS gate and B from IS to Boretto (fig. 1). The first is about $29 \mathrm{~km}$ long whilst the length of the second is almost $82 \mathrm{~km}$. All 4 tributaries join the river in reach B. The power station channel joins the river between the Adda confluence and Cremona.

At the upstream boundary (Piacenza station) and along the lower course of the tributaries, a long time series of data is available from ARPA (Regional Agencies for Environment) records. A 10-year-long time series of discharges (1964-1973) has been used both for Po river and the tributary inflows.

At the downstream station (Boretto), the stage-discharge relationship is provided by ARPA hydrological bulletins.

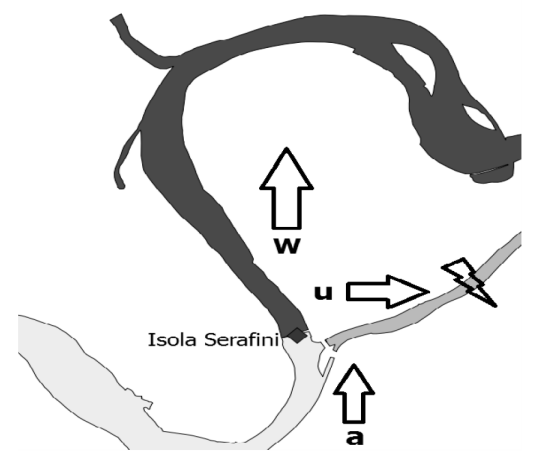

Figure 3: Scheme of the IS flow diversion.

When the hydropower plant is operating, the two stretches A and B are disconnected. The current operating rule of IS is reported in fig. 4 where $a$ is the inflow from upstream and $u$ the amount of water diverted to the hydropower plant. Consequently, $w=a-u$ is the discharge downstream of IS (fig. 3). An MEF (minimum environmental flow) of $100 \mathrm{~m}^{3} / \mathrm{s}$ is required through the meander and the minimum flow through the power station is $200 \mathrm{~m}^{3} / \mathrm{s}$. So, for incoming discharges $a$ not greater than $300 \mathrm{~m}^{3} / \mathrm{s}$, the power station is not working. When $a$ is greater than $300 \mathrm{~m}^{3} / \mathrm{s}$, all flow exceeding MEF is diverted to the turbines, up to the maximum permitted of $1000 \mathrm{~m}^{3} / \mathrm{s}$, so as to maximize electricity production. At $1100 \mathrm{~m}^{3} / \mathrm{s}$ then, the power station is working at its maximum; all incoming flow exceeding this value passes through the gate and flows into the meander. The station can work until the total discharge reaches approximately $4000 \mathrm{~m}^{3} / \mathrm{s}$; above this threshold, the head jump across the gate becomes too low for electricity generation. In addition, to avoid flooding risk, the turbines are switched off and the gate must be completely open to let the flood pass through. 


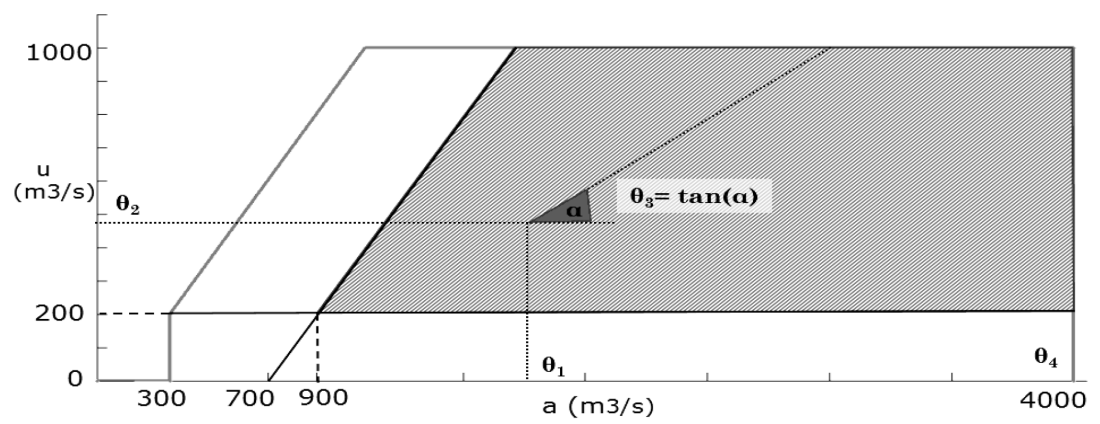

Figure 4: Domain space for $\mathrm{u}$.

When incoming flow $a$ is lower than $4000 \mathrm{~m}^{3} / \mathrm{s}$, the water level in the reservoir is kept constant at $41 \mathrm{~m}$ to maximize the head jump and the energy production.

For the upstream stretch A, the downstream boundary condition is the imposed water level. The operation rule of the gate (see the following section) provides the upstream boundary conditions for stretch B, both for the liquid and solid discharges. $w$ is the liquid discharge upstream reach $\mathrm{B}$; for the solid phase, if $Q_{s_{-} u p}$ is the solid discharge approaching IS, $Q_{s_{-} d w}$ (the solid discharge entering the meander) is calculated as follows:

$$
Q_{s_{-} d w}=Q_{s_{-} u p} \cdot 0.7 \cdot\left(\frac{w}{a}\right)^{1.7}
$$

The reduction coefficient 0.7 is applied to take into account the fact that not all of the eleven gates are open when power station is operating, so part of the sediment is stopped.

When the gate is fully open, instead, no flow is diverted to the channel $(u=0)$ and the two reaches are fully linked, so that continuity is satisfied also for sediment transport. Sediment contribution from tributaries is calculated with the Engelund-Hansen formula. The representative grain size $d_{s}$ decreases linearly along the reach from $1.5 \mathrm{~mm}$ to $0.5 \mathrm{~mm}[6]$.

\section{Design of experiments}

\subsection{Parameterization of the IS operating rule}

In order to build alternative regulation policies and to compare them in terms of river bed incision and hydropower production, we started parameterizing the current operation rule. The control variables of the problem are the amount of water $u$ derived for electricity production and the threshold above which the power station is switched off and reach A and B are hydraulically connected. 
The physical constraints for the variables are given by the MEF in the meander, the minimum and maximum flow through the turbines and the safety limit against flood risk. In addition, to enclose the alternatives in an effective domain, a critical value of the discharge $Q_{c r i t}$ must be defined, i.e. a value of discharge below which sediment transport can be considered negligible. Recent modeling studies on Po river [11] stated this $Q_{\text {crit }}$ equals $800 \mathrm{~m}^{3} / \mathrm{s}$. As a caution, this threshold has been decreased to $700 \mathrm{~m}^{3} / \mathrm{s}$. The domain is represented in fig. 4 with $a$ on the abscissas and $u$ on the ordinates.

Alternative policies should be planned to reach two main purposes: the increase of the sediment supply to the downstream reach and the increase of the transport capacity in the meander. Moreover, they should conflict as little as possible with the hydroelectricity production.

The operation rule can then be parameterized by 4 parameters, $\theta_{1}, \theta_{2}, \theta_{3}$ and $\theta_{4}$. The fourth parameter, $\theta_{4}$, is the discharge threshold at which the gates are completely open and stretches A and B are connected. This parameter affects, primarily, sediment supply to the downstream reach and secondly, also the transport capacity in the meander; $\theta_{1}, \theta_{2}$, and $\theta_{3}$ affect mainly transport capacity in the meander by reducing the discharge $u$ through the turbines (so increasing the discharge through the gate) when the power station is on. In detail, $\theta_{1}$ and $\theta_{2}$ are the coordinates of a point in the effective domain and $\theta_{3}$ is the slope of the line connecting $\left(\theta_{1}, \theta_{2}\right)$ with the boundary of the domain.

The operation rule can be synthesized as follows:

$$
\begin{cases}u=0 & \text { if } 0 \leq a \leq 200+M E F \\ u=\min (a-M E F, 1000) & \text { if } 200+M E F<a \leq \theta_{1} \\ u=\min \left(\theta_{2}+\theta_{3} \cdot\left(a-\theta_{1}\right), 1000\right) & \text { if } \theta_{1}<a<\theta_{4} \\ u=0 & \text { if } a>\theta_{4}\end{cases}
$$

The parameters have the following constraints:

$$
\left\{\begin{array}{l}
2000 \leq \theta_{4} \leq 4000 \\
900 \leq \theta_{1} \leq \theta_{4} \\
200 \leq \theta_{2} \leq \min \left(\theta_{1}-700,1000\right) \\
0 \leq \theta_{3} \leq 1
\end{array}\right.
$$

In addition to the business as usual (BAU) simulation, we ran 56 different alternative operating rules, represented by different grey lines in fig. 5, varying the 4 parameters within their domain. Experiments for different $\theta_{4}$, from 2000 to $4000 \mathrm{~m}^{3} / \mathrm{s}$ were simulated in order to assess the importance of restoring sediment connectivity more frequently between stretches A and B. Conversely, alternative options for diversion of the incoming water to the hydropower plant were implemented varying the values of $\theta_{1}, \theta_{2}$, and $\theta_{3}$, to assess their effects on transport capacity immediately downstream of the gate. 


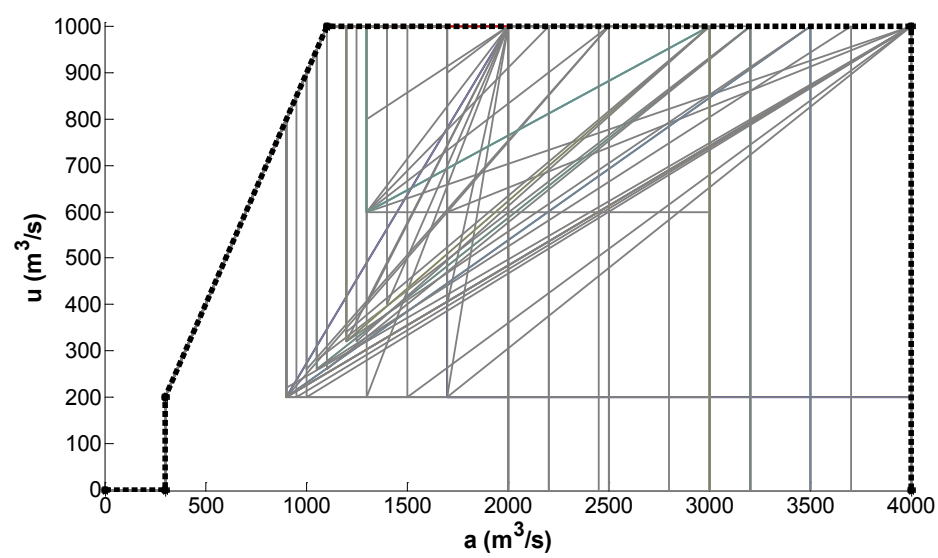

Figure 5: Set of experiments in the a-u domain. Each line represents a different operation rule defined by specific values of $\theta_{1}, \theta_{2}, \theta_{3}$ and $\theta_{4}$. BAU policy is the dashed black line.

\subsection{Indicators}

The two conflicting objectives of hydropower production and reduction of the incision are analysed through suitable indicators.

The numerical model provides a final configuration of the bed; a lowdischarge, steady flow simulation $\left(300 \mathrm{~m}^{3} / \mathrm{s}\right)$ is run over both the initial and final bed configurations. The two water surface profiles are then compared and an indicator of river bed incision is calculated measuring the difference in water levels, $z w_{\text {final }}-z w_{\text {initial }}$. This analysis is performed over the whole river stretch: 5 sub-reaches are considered (see fig. 1). To obtain the indicator $J_{i n c}$ for a specific sub-reach, water level variations are averaged over the cross sections belonging to it. A negative value of $J_{i n c}$ means that the river bed is undergoing degradation.

$$
J_{\text {inc }}=\left.\operatorname{avg}\left(z w_{\text {final }}-z w_{\text {initial }}\right)\right|_{\text {reach }}
$$

The attention is focused mainly on the reach next to Cremona: from an economic perspective this reach suffers the most from bed degradation, due to the presence of the industrial harbours.

Considering hydroelectricity, the immediate cost of hydropower $J_{h p}$ is the product of the daily energy production $P$ by a time-varying coefficient $\alpha$ :

$$
\begin{gathered}
J_{h p, t}=\alpha_{t} \cdot P_{t} \\
P_{t}=\rho g \eta_{t} u_{t} H_{t}
\end{gathered}
$$

In turn, the daily production $P$ is given by the product of water density $\rho$ and gravity acceleration $g$ by the flow release $u$ through the turbines, the head jump $H$ and the turbine efficiency $\eta$. $H$ is the difference between the water level upstream the gate and the level just downstream of the turbines $\left(\mathrm{h}_{\mathrm{up}}-\mathrm{h}_{\mathrm{down}}\right)$. Since the flow profile in the power station channel is not calculated, $h_{\text {down }}$ is 
given by an empirical relationship: $\mathrm{h}_{\text {down }}=f\left(u, \mathrm{~h}_{\text {junc }}\right)$. The dependent variables are the discharge $u$ flowing into the channel and the water level at the junction between the channel and the Po river $\left(\mathrm{h}_{\mathrm{junc}}\right.$, computed by the model).

\section{Results}

Figure 6 reports the results of all 57 experiments. The BAU policy leads to a hydropower generation worth 34.28 mil€/year and to a $J_{i n c}$ (see eqn. (12)) in Cremona of $-0.52 \mathrm{~m}$ in ten years. The square markers represent the pareto efficient solutions amongst the simulated ones. The results show that it is possible to markedly reduce the incision process in Cremona with a moderate loss in hydroelectricity production ( $2-5 \%$ of the production).

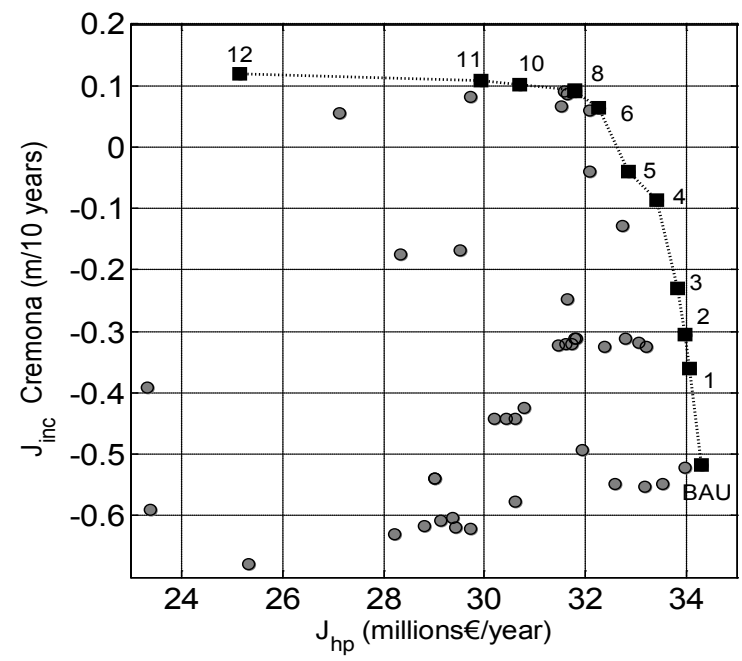

Figure 6: Incision in Cremona $\left(J_{i n c}\right)$ vs. hydropower value $\left(J_{h p}\right)$.

Table 1 reports the pareto efficient solutions ordered by decreasing incision. River bed incision is decreasing coherently, not only in Cremona but also in upstream reaches: results of $J_{i n c}$ in the two reaches of the meander (Me1 and $\mathrm{Me}$ 2, see fig. 1), indeed, show that the effects of alternative regulation policies are stronger closer to the gate; the two reaches further downstream (from $55 \mathrm{~km}$ downstream the gate) are not affected at all by the change in the operation rules and for this reason these results are not reported in the table.

The first columns of Table 1 report the values of $\theta$ parameters for the pareto efficient solutions. Please notice that setting $\theta_{2}$ to 1000 means not changing the BAU, except for $\theta_{4}$. The latter turned out to be the most sensitive driver of river bed evolution: values of $\theta_{4}$ around 2000 guarantee stopping incision in Cremona and in the meander, whereas significant changes in $\theta_{1}, \theta_{2}, \theta_{3}$ entail reducing hydropower production without relevantly affecting river incision. 
Table 1: $\quad$ Summary of results.

\begin{tabular}{|l|c|c|c|c|c|c|c|c|}
\hline ID & $\theta_{1}$ & $\theta_{2}$ & $\theta_{3}$ & $\theta_{4}$ & $J_{h p}(\mathrm{M} € / \mathrm{y})$ & \multicolumn{3}{|c|}{$J_{\text {inc }}(\mathrm{m})$} \\
\cline { 7 - 9 } & & & & & & $\mathrm{Me} 1$ & $\mathrm{Me} 2$ & Cremona \\
\hline BAU & 1700 & 1000 & 0 & 4000 & 34.28 & -1.49 & -0.83 & -0.52 \\
\hline 1 & 1700 & 1000 & 0 & 3200 & 34.07 & -0.97 & -0.47 & -0.36 \\
\hline 2 & 1700 & 1000 & 0 & 3000 & 33.97 & -0.82 & -0.35 & -0.30 \\
\hline 3 & 1700 & 1000 & 0 & 2800 & 33.83 & -0.59 & -0.16 & -0.23 \\
\hline 4 & 1700 & 1000 & 0 & 2450 & 33.40 & -0.04 & 0.23 & -0.09 \\
\hline 5 & 1700 & 1000 & 0 & 2200 & 32.83 & 0.19 & 0.35 & -0.04 \\
\hline 6 & 1700 & 1000 & 0 & 2000 & 32.27 & 0.49 & 0.52 & 0.06 \\
\hline 7 & 1700 & 900 & 1 & 2000 & 32.25 & 0.50 & 0.53 & 0.06 \\
\hline 8 & 1400 & 400 & 0.5 & 2000 & 31.79 & 0.65 & 0.58 & 0.09 \\
\hline 9 & 1700 & 400 & 0.3 & 2000 & 31.78 & 0.66 & 0.59 & 0.09 \\
\hline 10 & 1300 & 400 & 1 & 2000 & 30.71 & 0.62 & 0.53 & 0.10 \\
\hline 11 & 1200 & 320 & 1 & 2000 & 29.92 & 0.62 & 0.50 & 0.11 \\
\hline 12 & 900 & 200 & 0.5 & 2000 & 25.16 & 0.43 & 0.32 & 0.12 \\
\hline
\end{tabular}

It can be concluded that acting on sediment transport capacity in the meander alone, without increasing sediment supply in the downstream stretch, is ineffective in stopping incision and, at the same time, it conflicts with electricity production.

\section{Concluding remarks}

A mobile-bed, one dimensional numerical model has been used to test alternative operating rules for the dam of Isola Serafini, a run-of-the river electricity plant along the Po river in Italy. The control law of the gate has been parameterized with four parameters, that control the flow diverted to the hydropower plant turbines and the discharge threshold above which the gate is fully open and the hydropower plant is inactive. 57 experiments have been planned and run, measuring the electricity generation and the river bed evolution up to $80 \mathrm{~km}$ downstream of the gate.

The results are encouraging and show that with a moderate loss in hydroelectricity production the decrease in incision can be remarkable. The quantification of the trade-off between hydropower production and river bed incision provides river managers and stakeholders involved in river management with precious information to plan appropriate and commonly agreed compensation and rehabilitation measures.

River geomorphology has become a key aspect of river management over the last few years [14] and geomorphic processes significantly affect various environmental services that fluvial systems provide to our society, ranging from flood mitigation to ecological aspects. The economical quantifications of these direct and indirect ecosystem services are difficult to estimate and are a matter of recent research [5], but their evaluation can no longer be neglected when 
planning modern catchment management strategies. Our case study opens up promising possibilities in embedding fluvial geomorphic processes in the design of optimal regulation policies of reservoirs.

\section{References}

[1] Bleninger, T., Fenton, J., and Zentgraf, R., One-dimensional flow modelling and a case study of the river Rhine. River Flow 2006, Proc. Int. Conf. on Fluvial Hydraulics, eds. R.M.L. Ferreira, E.C.T.L. Alves, J. G. A. B. Leal \& A.H. Cardoso, pp. 1963-1972, Lisbon 2006.

[2] Castelletti, A., Pianosi, F., and Soncini-Sessa, R., Integration, partecipation and optimal control in water resources planning and management. Applied Mathematics and Computation, 206(1), 21-33, 2007.

[3] Chaudhry, M. H., Open Channel Flow, 2nd ed. Springer, Berlin, pp. 377379, 2007.

[4] Engelund, F. and Hansen, E., A monograph on sediment transport in alluvial streams, Teknisk Forlag, Copenhagen, 1967.

[5] Gilvear, D. J., Spray, C. J., and Casas-Mulet, R., River rehabilitation for the delivery of multiple ecosystem services at the river network scale. Journal of Environmental Management, 126(0), 30-43, 2013.

[6] Italian Ministry of Agriculture, Po AcquAgricolturAmbiente - 2: l'alveo e il delta, (Po: Water, Agriculture and Environment - volume 2: the river bed and the delta) Il Mulino, Bologna, pp. 184-195, 1990 (in Italian).

[7] Lamberti, A. and Schippa, L., Studio dell'abbassamento dell'alveo del fiume Po: previsioni trentennali dell'abbassamento a Cremona, Supplement to Navigazione Interna 3/4, July-December 1994 (in Italian).

[8] MacCormack, R.W., The effect of viscosity in hypervelocity impact cratering. American Institute of Aeronautics and Astronautics Electronic Library, pp. 69-354, 1969.

[9] Newson, M. D., and Large, A. R., "Natural" rivers, "hydromorphological quality" and river restoration: a challenging new agenda for applied fluvial geomorphology. Earth Surface Processes and Landforms, 31, 1606-1624, 2006.

[10] Petts, G. E., and Gurnell, A. M., Dams and geomorphology: Research progress and future directions. Geomorphology, 71(1-2), 27-47, 2005.

[11] Rosatti G., Armanini, A., Galletta, V., Vergnani, M., and Cerchia, F., L'uso dei pennelli per la riduzione della barra forzata in prossimità del punto di inflessione tra due curve susseguenti: uno studio numerico relativo al Po. Atti del $31^{\circ}$ Convegno di Idraulica e Costruzioni Idrauliche, Morlacchi, Perugia 2008 (in Italian).

[12] Schippa, L. and Pavan, S., Analytical treatment of source terms for complex channel geometry. Journal of Hydraulic Research, 46(6), pp. 753763, 2008.

[13] Schippa, L. and Pavan, S., Bed evolution numerical model for rapidly varying flow in natural streams. Computers \& Geosciences, 35, pp. 390402, 2009. 
[14] Simon, A., and Rinaldi, M., Disturbance, stream incision, and channel evolution: The roles of excess transport capacity and boundary materials in controlling channel response. Geomorphology, 79, 361-383, 2006.

[15] Valiani, A. and Begnudelli, L., Divergence form for bed slope source terms in shallow water equations. Journal of Hydraulic Engineering, 132(7), pp. 652-665, 2006. 